\title{
Bilateral Dens in Dente in Maxillary Laterals: A Case Report
}

\author{
Rameshwari Raol* and Parth Joshi \\ Department of Pediatric Dentistry, we smile kids dental clinic, Vadodara, India
}

*Corresponding author: Rameshwari Raol, Department of Pediatric Dentistry, we smile kids dental clinic, Vadodara, India

\begin{abstract}
Dens invaginates is a defect categorized by a prominent lingual cusp and centrally located fossa. It occurs due to early invagination of the enamel epithelium into dental papilla of the underlying tooth germ. The affected teeth show a deep invagination of enamel as well as dentin initiating from foramen caecum or tip of the cusps and may extend even into the root. The teeth that are most frequently involved teeth are the maxillary lateral incisors, there might also occur a bilateral involvement. In this anomaly there can be seen several morphologic variations and it may lead to early pulpal involvement from the caries progressing into the pulp from lingual pit. The treatment varies from a preventive restoration to endodontic therapy, depending on the severity of the case. The present case report refers to one such case having a deep lingual pit bilaterally in both the maxillary permanent lateral incisors.
\end{abstract}

\section{Introduction}

Dens invaginatus is a rare malformation of teeth, showing various morphological variations. Radiographically the teeth show an invagination of enamel and dentin extending up to the pulp cavity or the roots. This malformation was described earliest by Ploquet [1], who discovered this anomaly in a whale's tooth [2]. Dens invaginatus in a human tooth was first described by a dentist Socrates' in 1856 [3]. 'Anomalous cavities in human teeth were reported by Mühlreiter [4] in 1873, Baume [5] in 1874 and Busch [6] in 1897 reported about this anomaly as well. In 1887 Tomes [7] described the dens invaginatus as: The enamel of the coronal portion is generally well developed but we tend to find a small depression in its centre that appears to be a dark spot. On division of the tooth longitudinally, there occurs a dark centre of depression that is a blocked orifice within the tooth. If the section be a fortunate one, we shall be able to trace the enamel as it is continued from the exterior of the tooth through the opening into the cavity, the surface of which is lined completely with this tissue' [7]. There are various reports on cases of dens invaginatus malformation in the dental literature [8-11]. Synonyms for this anomaly include:

a) Dens in dente,

b) Invaginated odontome, c) Dilated gestant odontome,

d) Dilated composite odontome,

e) Tooth inclusion,

f) Dentoid in0 dente.

\section{Case Report}

A 12-year-old female patient referred to the Pedodontics department with the complaint of irregularly arranged teeth. General health of the patient was normal and medical history was not relevant. Clinical examination revealed teeth 12 and 22 with a lingual pit. The pre-operative photographs were taken for the same (Figure 1). An intraoral Periapical radiograph was also taken for both the teeth, which revealed deep lingual pits involving the coronal part of teeth (Figure 2). As the teeth showed only incisal invaginations, and no pulpal involvement preventive treatment was selected. Also, if the pits were left untreated, it would harbor irritants and microorganisms further leading to caries. And as these pits were deep enough, the caries would progress rapidly into the pulp and cause pulpal infection leading to the need for endodontic treatments. 


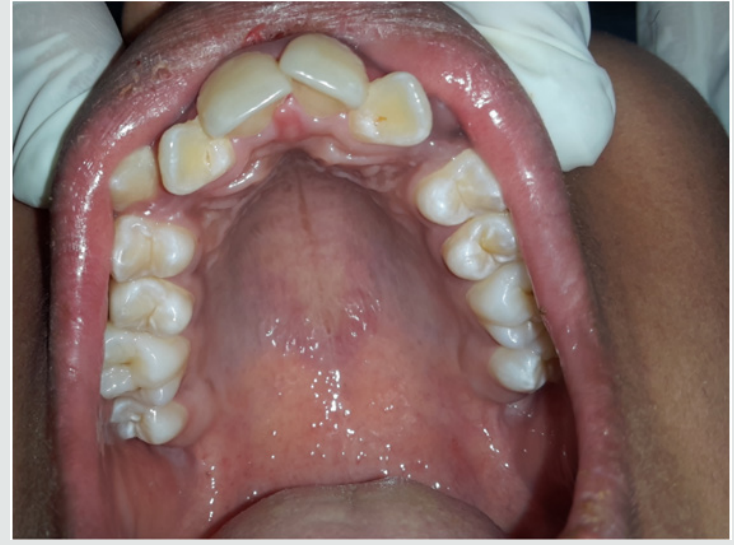

Figure 1: Pre-operative photograph.

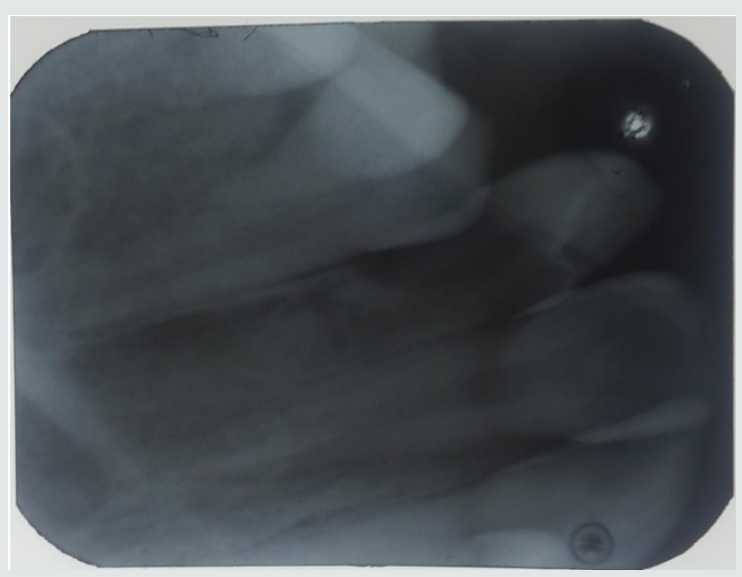

Figure 2a: IOPA.

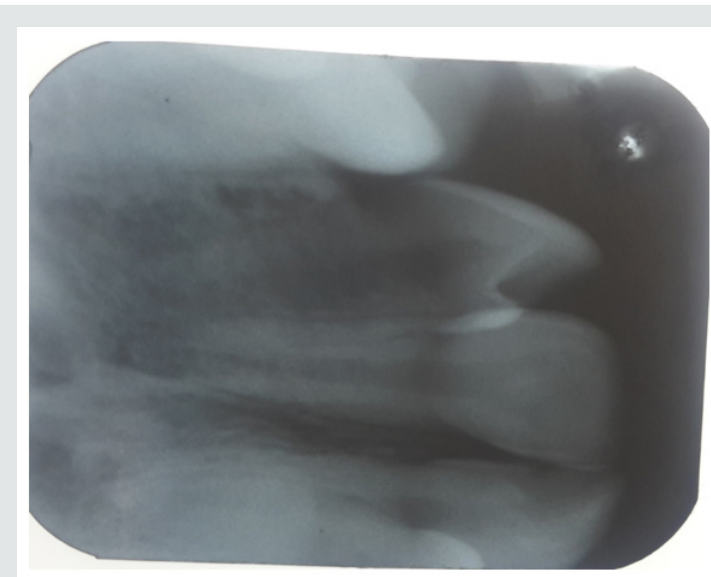

Figure 2b: IOPA.

\section{Treatment Done}

Following the oral prophylaxis, rubber dam placement was done for 12 and 22 (Figure 3). The teeth were initially washed, cleaned and dried. After that acid etching was performed using $37 \%$ phosphoric acid for 20 seconds. It was then washed and dried. Following that dentin bonding agent was applied with the applicator tip and cured for 20 seconds. The pits were then restored with flowable composite bilaterally (Figure 4). The teeth were then examined for any excess material and later finishing was done. The occlusion was also checked for any interference followed by post-operative photographs (Figure 5). Furthermore, the child was referred for orthodontic consultation.

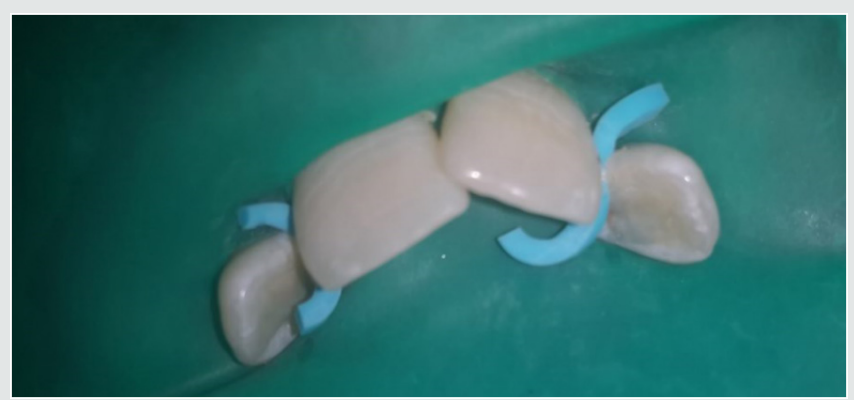

Figure 3: Rubberdam placement.

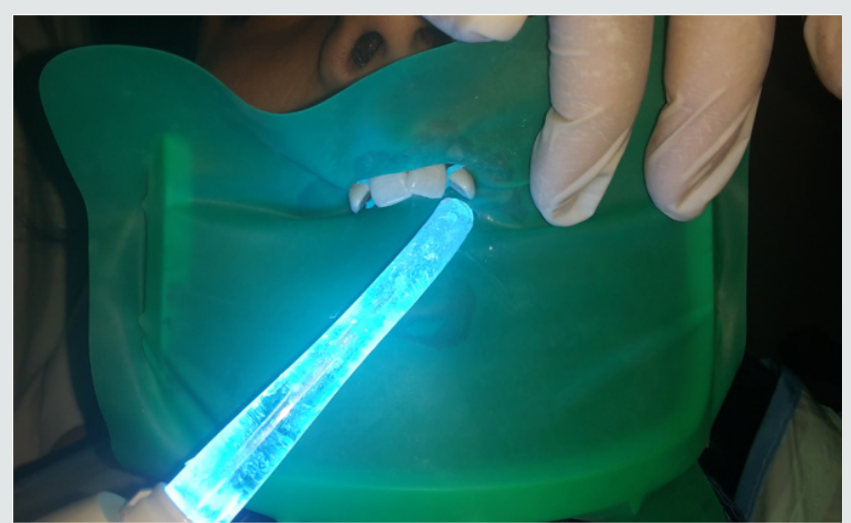

Figure 4: Composite restoration.

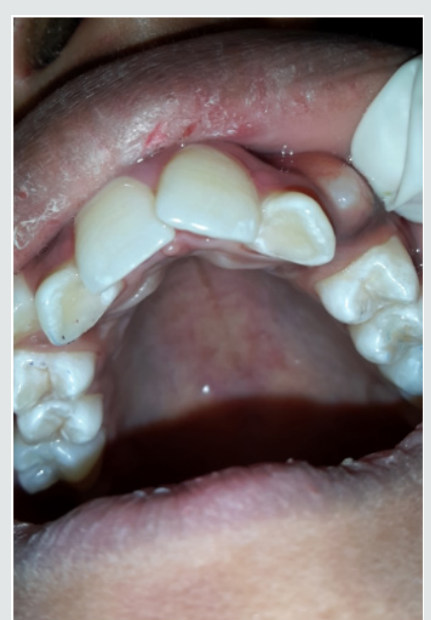

Figure 5: Post-operative view.

\section{Discussion}

Dens Invaginatus has several variations of it. Oehlers gave a classification for various types of dens invaginatus [12]:

a) Type I: an enamel-lined minor form occurring within the confines of the crown not extending beyond the amelocemental junction. 
b) Type II: an enamel-lined form which invades the root but remains confined as a blind sac. It may or may not communicate with the dental pulp.

c) Type III: a form which penetrates through the root perforating at the apical area showing a 'second foramen' in the apical or in the periodontal area. There is no immediate communication with the pulp. The invagination may be completely lined by enamel, but frequently cementum will be found lining the invagination.

\section{Prevalence of Dens Invaginatus}

The teeth mainly affected are maxillary lateral incisors and bilateral occurrence is not rare, they occur in almost $43 \%$ of all cases [13]. Swanson \& McCarthy (1947) were the foremost to present bilateral dens invaginatus malformation, Conklin (1968) presented a patient with both maxillary central and lateral incisors affected bilaterally, and Burton et al. (1980) reported a case with six teeth involved, the maxillary incisors as well as the maxillary canines. Krolls (1969) also detected dental invaginations in maxillary central incisors and in many maxillary and mandibular premolars in a single patient. Conklin (1978) found the malformation in four mandibular incisors in one patient. There are many theories described in the literature to explain about the dental coronal invaginations some of them being:

a) The bulking of the enamel organ was thought to be caused due to the growth pressure of the arches $[14,15]$.

b) Focal failure of the growth of the inner enamel epithelium leads to the invaginations; however, the surrounding epithelium continues to grow and engulfs the static area [11].

c) The invagination is due to the aggressive proliferation of a part of the inner enamel epithelium invading the dental papilla. It was thought as a 'benign neoplasm of limited growth [16].

d) Protrusion and distortion of the enamel organ is thought to cause an enamel lined channel terminating at the cingulum or at the incisal tip. This might also lead to an irregular crown formation $[17,18]$.

e) The 'twin-theory' [18] suggested a fusion of two toothgerms to be the causative factor.

f) Infection was also considered to be responsible for the anomaly [19].

g) Trauma was thought to be a reason, but they could not adequately explain why just maxillary lateral incisors were affected and not central incisors [20].

h) Most authors consider dens invaginatus as a deep folding of the foramen coecum during tooth development which may even result in a second apical foramen [3].

i) On the other hand, the invagination also may start from the incisal edge of the tooth. Genetic factors cannot be expelled
(Grahnen 1962, Casamassimo et al. 1978, Ireland et al. 1987, Hosey \& Bedi 1996).

\section{Clinical Features}

Due to the invagination there is just a thin layer of enamel and dentin left, which thus allows several microbes into the pulpal space easily. In some of the cases there is a complete enamel lining present. Also, channels may be present between the invagination and the pulp chamber. Pulp necrosis hence occurs in the earlier stages, within a few years of eruption and may be even before the root closure. The sequelae of untreated coronal invaginations can be as follows:

a) Abscess formation.

b) Retention of neighboring teeth.

c) Displacement of teeth.

d) Cysts, or Internal resorption.

\section{Treatment Modalities}

Preventive and restorative treatment should be opted for teeth with deep palatal or incisal invaginations and should be treated by fissure sealing [21]. Also, composite resin restoration followed by pit and fissure sealant can be done in the required cases [21]. Root canal treatment, surgical treatment and extraction of teeth should be done in severe cases wherein there is radicular invagination and pulpal involvement.

\section{Conclusion}

The clinician should be aware of occurrence of such tooth anomalies and should do a thorough clinical diagnosis as these anomalies are not rare. Earlier diagnosis and treatment of such cases can prevent further complications such as endodontic therapies and extractions. Hence the needed treatment should be done as early as possible and a periodic follow up should be maintained.

\section{References}

1. Schaefer H (1955) Zur Klinik des dens in dente. Deutsche Zahnärztliche Zeitschrift 10: 988-993.

2. Westphal A (1965) Ein kleines Kuriosum um den ersten 'Dens in dente'. Zahnärztliche Mitteilungen 55: 1066-1070.

3. Schulze C (1970) Developmental abnormalities of the teeth and the jaws. In: Gorlin O, Goldman H, Eds. Thoma's Oral Pathology pp. 96-183.

4. Mühlreiter E (1873) Die Natur der anomalen Höhlenbildung in oberen Seitenschneidezahne. Deutsche Vierteljahresschrift für Zahnheilkunde 13: $367-72$.

5. Baume R (1874) Zahnmibbildungen. I. Ein Zahn im Zahne. Deutsche Vierteljahresschrift für Zahnheilkunde 14: 25-29.

6. Busch N (1897) Über Verschmelzung und Verwachsung der Zähne des Milchgebisses und des bleibenden Gebisses. Deutsche Monatsschrift für Zahnheilkunde 15, 469-86.

7. Tomes J (1887) A System of Dental Surgery,( $3^{\text {rd }}$ Edn). J \& A Churchill, London, UK, pp. 652-655. 
8. Miller WD (1901) Einige seltene Zahnanomalien. Deutsche Monatsschrift für Zahnheilkunde 19: 397-410.

9. Lejeune F, Wustrow P (1920) Zwei Fälle einer eigenartigen Zahnmibbildung. Deutsche Monatsschrift für Zahnheilkunde 38: 15-22.

10. De Jonge Cohen Te (1925) Ein neuer Beitrag zur Morphogenese des 'dens in dente'. Vierteljahrschrift für Zahnheilkunde 41: 125-30.

11. Kronfeld R (1934) Dens in dente. Journal of Dental Research 14: 49-66.

12. Oehlers FA (1957a) Dens invaginatus. I. Variations of the invagination process and associated anterior crown forms. Oral Surgery, Oral Medicine and Oral Pathology 10: 1204-1218.

13. Grahnen H, Lindahl B, Omnell K (1959) Dens invaginatus. I. A clinical, roentgenological and genetical study of permanent upper lateral incisors. Odontologisk Revy 10: 115-137.

14. Euler H (1939) Die Anomalien, Fehlbildungen und Verstümmelungen der menschlichen Zähne. München, Germany, pp. 62-67.
15. Atkinson SR (1943) The permanent maxillary lateral incisor. American Journal of Orthodontics 29: 685-698.

16. Rushton MA (1937) A collection of dilated composite odontomas. British Dental Journal 63: 65-85.

17. Oehlers FA (1957b) Dens invaginatus. II. Associated posterior crown forms and pathogenesis. Oral Surgery, Oral Medicine and Oral Pathology 10: 1302-16.

18. Bruszt P (1950) Über die Entstehung des 'Dens in dente'. Schweizer Monatsschrift für Zahnheilkunde 60: 534-542.

19. Fischer CH (1936) Zur Frage des Dens in dente. Deutsche Zahn-, Mundund Kieferheilkunde 3: 621-634.

20. Gustafson G, Sundberg S (1950) Dens in dente. British Dental Journal 88: 83-88, 111-122, 144-146.

21. Hulsmann M (1997) Dens invaginatus: aetiology, classification, prevalence, diagnosis, and treatment considerations. International Endodontic Journal 30(2): 79-90.

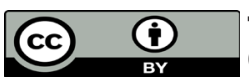

This work is licensed under Creative Commons Attribution 4.0 License

To Submit Your Article Click Here: Submit Article

DOI: $10.32474 /$ IPDOAJ.2019.02.000147

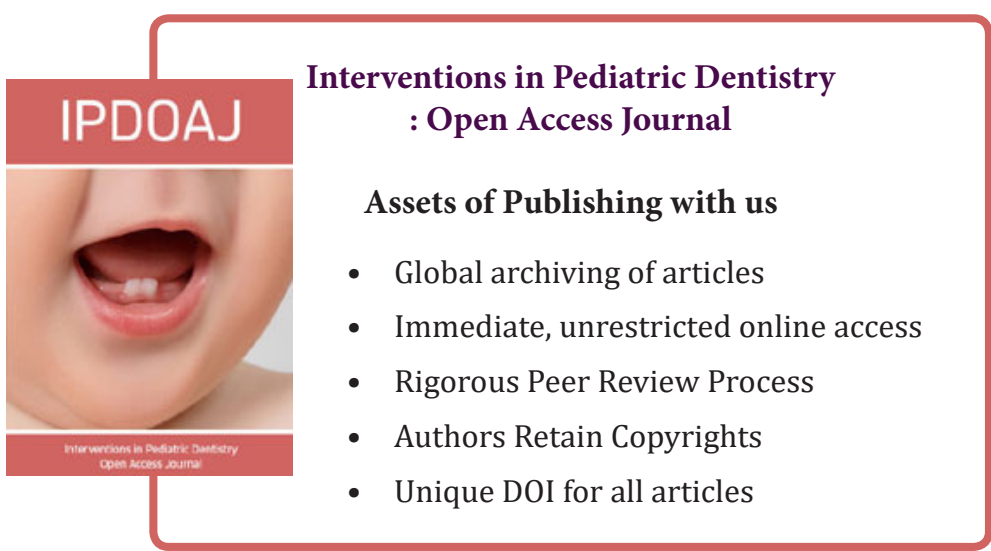

